\title{
Atividade física e saúde: da concepção ao envelhecimento
}

\section{Pedro C Hallal}

Universidade Federal de Pelotas -

Editor-chefe da Revista Brasileira de Atividade Física e Saúde
Entre os dias 09 e 12 de novembro de 2011, os principais pesquisadores nacionais da área de atividade física e saúde estarão reunidos na cidade de Gramado, RS durante a realização do VIII Congresso Brasileiro de Atividade Física e Saúde. O evento desse ano aborda a temática "Atividade física e saúde: da concepção ao envelhecimento", objetivando discutir os níveis de atividade física, suas causas, consequências e estratégias de promoção ao longo do ciclo vital. Para isso, a comissão organizadora local, em parceria com a Sociedade Brasileira de Atividade Física e Saúde, está preparando uma programação que aborde a atividade física nas diferentes etapas do ciclo vital, desde a vida intra-uterina até o envelhecimento.

Além dos convidados nacionais, contaremos com conferencistas internacionais, mantendo a tradição do evento iniciado em Florianópolis e expandido para o resto do Brasil com a criação da Sociedade Brasileira de Atividade Física e Saúde em 2007. Na área de ciclo vital, contaremos com uma conferência do Prof. Reynaldo Martorell, da Emory University (EUA), o qual falará sobre os 1000 dias críticos do início da vida. Ainda nessa área, o Prof. Cesar Victora da Universidade Federal de Pelotas, membro da Academia Brasileira de Ciências, ministrará uma conferência sobre saúde pública e as metas de desenvolvimento do milênio. Especificamente na área de atividade física, teremos conferências com a Profa I-Min Lee da Harvard University (EUA) e do Prof. Steven Blair do Cooper Institute (EUA).

A previsão é que mais de 1000 pessoas participem do evento, o qual contará com mini-cursos, mesas-redondas, palestras, conferências e apresentação de trabaIhos, tanto no formato oral quanto na forma de pôster. O evento ocorrerá no período do Natal Luz em Gramado, de forma que o potencial turístico da serra gaúcha possa ser aproveitado ao máximo por nossos participantes.

Contamos com a submissão de seus melhores trabalhos para o evento e esperamos você em Gramado em Novembro. 